\title{
Towards green carbon fibre manufacturing from waste cotton: a microstructural and physical property investigation
}

\author{
Pravin Jagdale ${ }^{1}$, Elias P. Koumoulos ${ }^{2}$, Irene Cannavaro ${ }^{1}$, Aamer $\mathrm{Khan}^{1}$, Micaela Castellino ${ }^{3}$, \\ Dimitrios A. Dragatogiannis ${ }^{2}$, Alberto Tagliaferro ${ }^{1}$, and Costas A. Charitidis ${ }^{2, *}$ \\ ${ }^{1}$ Politecnico di Torino, Department of Applied Science and Technology (DISAT), Torino 10129, Italy \\ ${ }^{2}$ RNanoLab, National Technical University of Athens, School of Chemical Engineering, 9 Heroon Polytechniou St., Zographos, \\ Athens 15780, Greece \\ ${ }^{3}$ Center for Space Human Robotics, Istituto Italiano di Tecnologia, Torino 10129, Italy
}

Received: 7 February 2017 / Accepted: 23 June 2017

\begin{abstract}
The work presents the usefulness of cotton fibre waste as a source of carbon fibre (CF) by pyrolysis. Different pyrolysis temperatures were studied to assess the surface and structural changes during carbonisation. The structural and surface modification of fibres during carbonisation was studied by thermogravimetric analysis (TGA), Field Emission Scanning Electron Microscopy (FESEM), and Raman spectroscopy. Lowpressure plasma employed for surface functionalization treatment in presence of oxygen was conducted. The surface modification was analysed and compared by X-ray Photoelectron Spectroscopy (XPS) and contact angle analysis. Carbon fibre structural strength was studied using nanoindentation. The carbon fibres before and after functionalization revealed a significant change in surface hydrophilicity. In nanoindentation, the maximum displacement of carbon fibre produced at $400{ }^{\circ} \mathrm{C}$ is higher when compared to treatment of $600{ }^{\circ} \mathrm{C}$ and $800{ }^{\circ} \mathrm{C}$, for identical applied load, revealing lower resistance to applied load, while the carbon fibre produced at $600{ }^{\circ} \mathrm{C}$ has the least displacement, i.e. higher resistance to applied load. Enhancement of material strength (through resistance to applied load) after surface functionalization is evidenced for the case of carbon fibre produced at $400^{\circ} \mathrm{C}$ and no effect for carbon fibre (both plain and functionalized) produced at $800^{\circ} \mathrm{C}$.
\end{abstract}

Keywords: waste cotton / carbon fibres / nanoindentation / surface tension / pyrolysis

\section{Introduction}

Natural fibres are available for use in various applications and for replacement of the traditional polymeric fibres [1-3] in composites manufacturing. These fibres exhibit several benefits compared to traditional polymer and glass fibres, that is, low density, enhanced mechanical properties, nonabrasive properties, low acoustic and thermal conductivity, biosourcing, and biodegradability [3-5]. Among all these natural fibre types, cotton is the one of the most common and popular natural cellulose fibres [6,7]. Cotton fibres are one of the purest sources of cellulose, consisting of $90-95 \%$ cellulose [8]. Consumption of cotton fibres in the world is increasing significantly along with waste cotton generation [9]. Unfortunately, recycling of waste cotton fibres in any form requires processing cost and recycling quality of fibres. Manufacturing sector has been focusing on blending recycled fibres with long-staple fibres in order to overcome this drawback. So far, no evident research has come up with a

* e-mail: Charitidis@chemeng.ntua.gr reliable large-scale solution. Waste cotton fibres are a potential bio-renewable, negligible cost, easy and massive availability with approximately $44 \mathrm{wt} . \%$ of carbon [10]. This fact makes waste cotton fibres a favourable candidate as a precursor for manufacturing carbon fibres (CFs) [11]. Carbon fibre based industries and researchers express interest in search of the suitable, low-cost, and effective source of precursors to fulfil the industrial demands of CFs [12-15]; in the last decade, issues concerning environmental pollution and the increasing awareness of limited resources have motivated the scientific community to study and optimize renewable alternatives to traditional petroleumderived plastics, like biobased composite materials that are sourced from carbon-neutral feedstocks [14]. Towards this, waste cotton fibres are used as a precursor for qualitative and quantitative production of CFs through pyrolysis, an easy and industrially commonly reported method [16-19] for conversion of waste cotton fibres to CFs. The pyrolysis parameters such as temperature, heating ramp rate, holding time, gas flow rate and preconditioning of the sample are important for carbonaceous materials [18] and CF production considering the endues applications. 


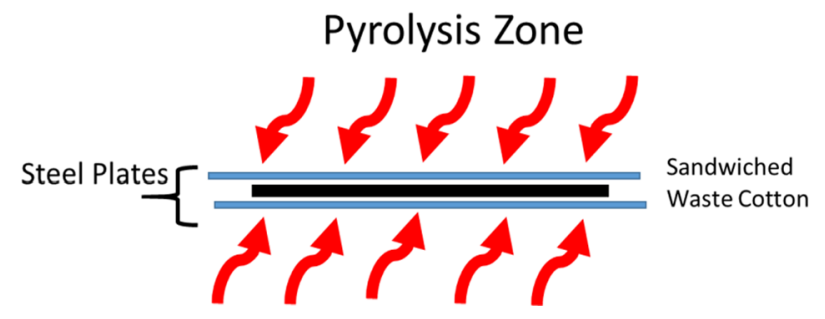

Fig. 1. Waste cotton fibres in pyrolysis chamber.

Altering the pyrolysis parameters affects the final morphology, yield, structural properties of CFs. In this article, the process of waste cotton pyrolysis is studied in detail. Surface modification of the CFs also alters their properties. Vacuum plasma treatment was adopted due to intriguing benefits such as effective surface modification, easy to operate, low cost and controlled treatment as compared to other surface modification techniques [20,21]. The surface modification and temperature dependent behaviour of waste cotton based CFs were studied by comparing the structural properties, wettability and response to nanoscale deformation.

\section{Material and methods}

\subsection{Thermo-gravimetric analysis (TGA)}

Prototype pyrolytic reaction was performed on Cotton fibres in TGA (Mettler Toledo, TGA/SDTA851). TGA was performed on cotton fibres in argon $(100 \mathrm{ml} / \mathrm{min})$ atmosphere. The heating ramp rate was maintained at $5{ }^{\circ} \mathrm{C} / \mathrm{min}$ from 25 to $800^{\circ} \mathrm{C}$. The analysis revealed the mass losses of cotton fibres with temperature during pyrolysis (selection of appropriate pyrolysis parameters for conversion of cotton fibres to CFs).

\subsection{Pyrolysis of waste cotton fabrics to attain carbon fibres}

Cleaned plain waste cotton fibre (100\% purity) in fabric form was selected as a precursor for CF. Cotton fabric used for pyrolysis was cut in the dimension of $15 \mathrm{~cm} \times 2.5 \mathrm{~cm}$ $\times 0.1 \mathrm{~cm}$. This is the maximum acceptable dimension in the Pyrolysis steel reactor (Carbolite TZF12/65/550). The sample was processed in a sandwich-like form between two steel plates (Fig. 1) to maintain the stress during pyrolysis. The controlled stress allows the fibres to shrink uniformly but also protects the shape and orientation of the cotton fabric during the pyrolysis process.

The type of application of the resulting carbon fibres usually determines the temperature of pyrolysis. Precursor holding time and temperature in the pyrolysis process affect their properties such as carbonisation/graphitization, final yield, and electrical conductivity of the final yield of carbonaceous fibres [22]. Considering the above points and TGA result, the following temperatures (Tab. 1) were selected for pyrolysis. The carbonisation and graphitization of cotton fibres were carried out in an inert atmosphere containing Argon gas [23]. While nitrogen is a commonly used gas in pyrolysis, argon was selected based on its ability
Table 1. Pyrolysis condition for CFs.

\begin{tabular}{lllll}
\hline No & Sample & $\begin{array}{l}\text { Pyrolysis temp. } \\
\left({ }^{\circ} \mathrm{C}\right)\end{array}$ & $\begin{array}{l}\text { Duration } \\
(\mathrm{min})\end{array}$ & Inert gas \\
\hline 1 & CF 400 & 400 & 60 & Argon \\
2 & CF 600 & 600 & 60 & Argon \\
3 & CF 800 & 800 & 60 & Argon \\
\hline
\end{tabular}

to provide improved strength to the carbon fibre (higher density and viscosity of argon). To avoid the thermal shock to cotton fibres by instant heating, a minimum heating ramp rate $\left(10^{\circ} \mathrm{C} / \mathrm{min}\right)$ of the furnace was chosen. Achieved pyrolysis conditions were further maintained for additional 60 min period to confirm the equilibrium and completion of the reaction.

In order to study the impact of CFs surface modification on wettability and nanoindentation properties, the CFs surface was treated in low-pressure oxygen plasma (Plasmafab508). For surface modification, CFs were kept in vacuum plasma $(100 \mathrm{~W})$ for $5 \mathrm{~min}$. $50 \mathrm{mT}$ Torr vacuum was maintained during the treatment. Oxygen was used for the CFs surface functionalization in plasma treatment.

\subsection{Micro-Raman}

Raman Spectroscopy (Renishaw) measurement was performed on carbonised and functionalized CFs. The green laser $(\lambda=514.5 \mathrm{~nm})$ with beam size of $\sim 2 \mu \mathrm{m}$ of diameter was set with $50 \times$ magnification microscope. A $10 \mathrm{~s}$ exposure time $\left(400-3500 \mathrm{~cm}^{-1}\right)$ with 20 scans was used to get the noise free graph.

\subsection{Nanoindentation}

The variation of resistance to applied load values of the fabric with different treatments was studied through nanoindentation load-unload curves. Load-unload curves were extracted using a Berkovich indenter under load control of $10 \mathrm{~s}$ load and unload times ( $2 \mathrm{~s}$ of hold time) protocol and a pre-load of $0.1 \mu \mathrm{N}$, while 25 measurements were performed on each sample. Due to the weaving of the fibres, there are large gaps between fibre bundles. To diminish the probability of encountering such gaps during indentation, a $5 \times 5$ array with a grid length of $70 \mu \mathrm{m}$ was used. Consecutive measurements are therefore more likely to probe into a uniform region, be it a gap or a fibre bundle.

\subsection{Surface wettability}

A prototype contact angle apparatus was used in this study. Prior to contact angle measurement, a Rame-Hart calibration was conducted. The experiment was conducted under room temperature. Due to weave texture of carbon fibres, when measurements were performed on carbon fibres with the water drop, the water drop was immediately absorbed therefore making the measurements become impossible to conduct measurements. To avoid the error, 


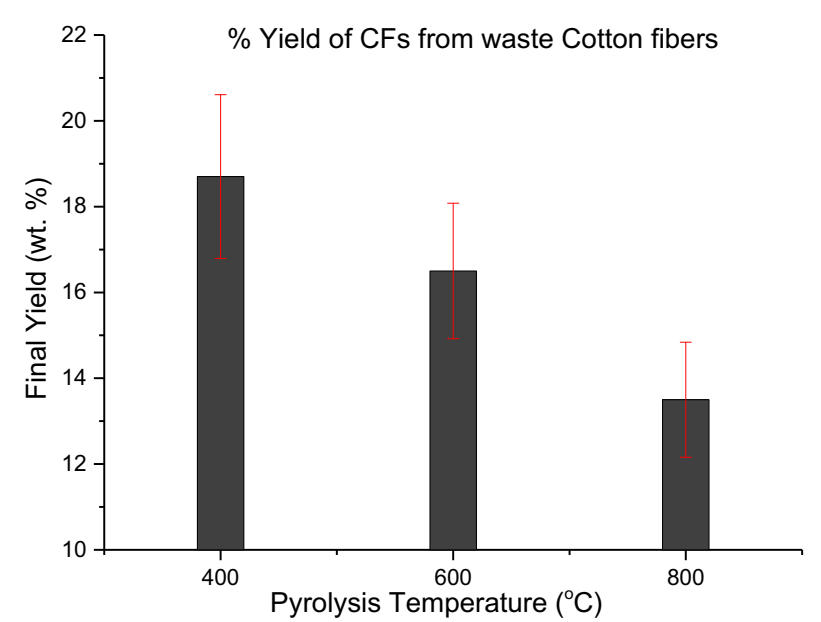

Fig. 2. Representation of bean-shaped cross section of a single cotton fibre and structure formation during pyrolysis.

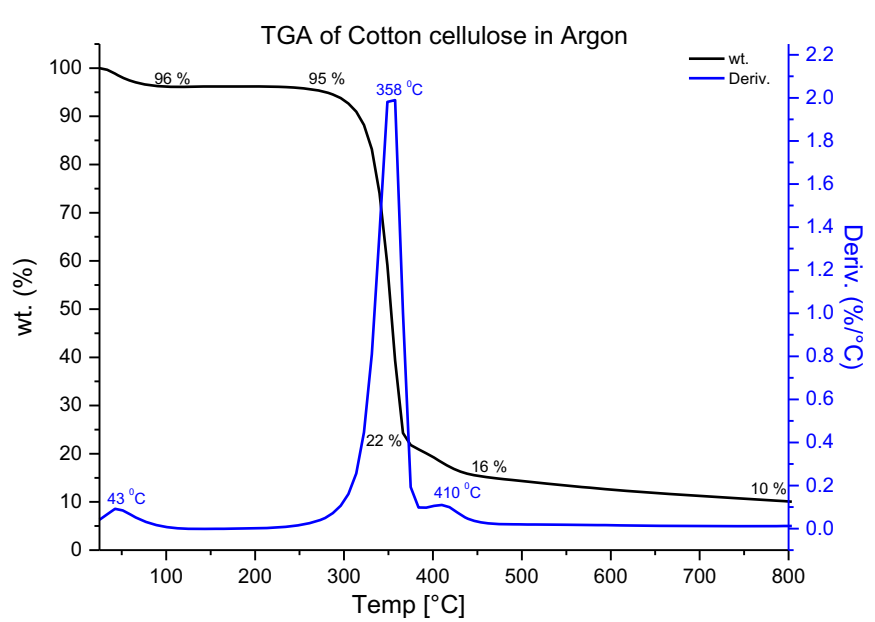

Fig. 4. TG-DTA of cotton fibres in argon.
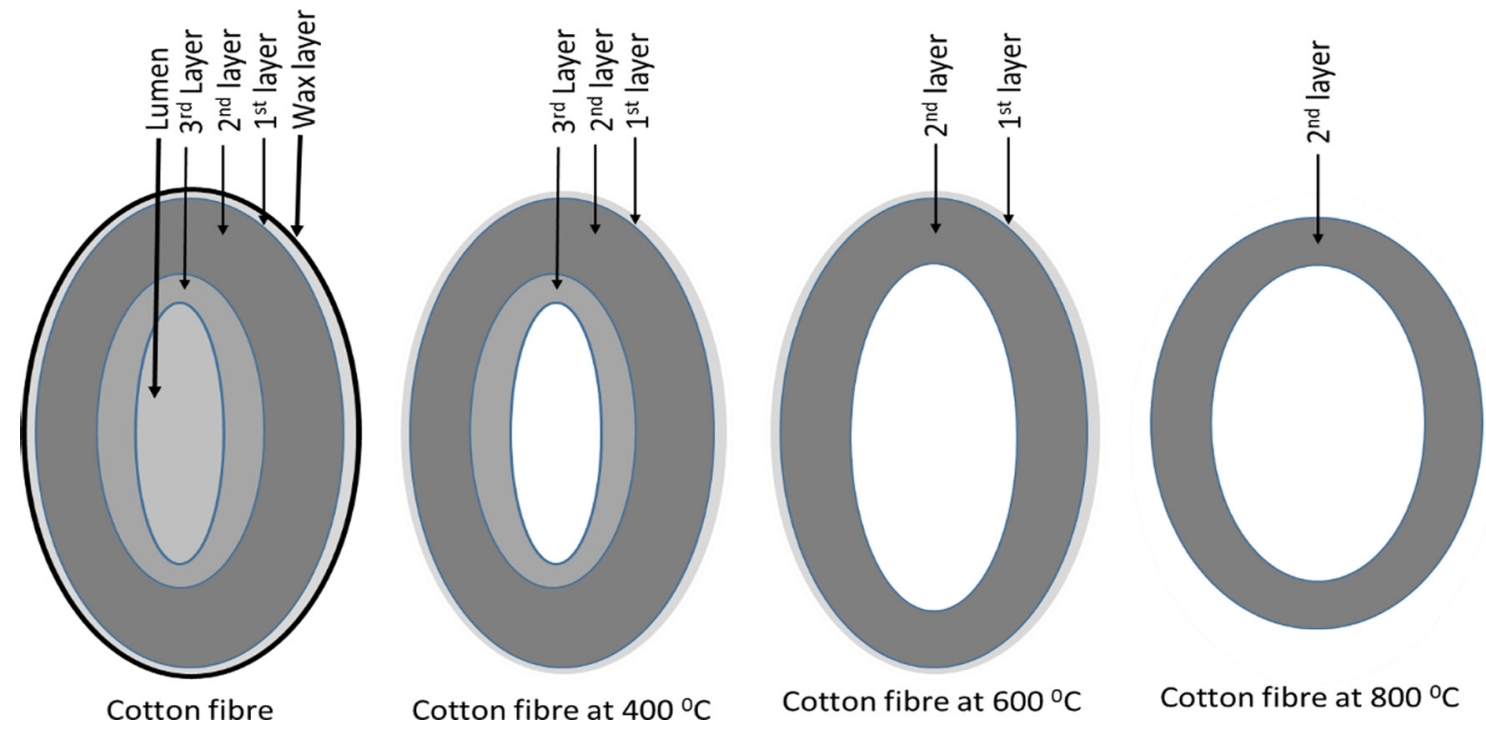

Cotton fibre at $600^{\circ} \mathrm{C}$

Cotton fibre at $800^{\circ} \mathrm{C}$

Fig. 3. Wt.\% yield of carbon fibres from waste cotton fibres in pyrolysis.

water was replaced with high-density glycerol [24]. Glycerol drop $(11.5 \mu \mathrm{l})$ was used to measure the CA on carbon fibre surface.

\subsection{X-ray Photoelectron Spectroscopy (XPS)}

XPS was carried out by using a PHI 5000 Versa Probe (Physical Electronics) system. The X-ray source is a monochromatic $\mathrm{Al} \mathrm{K \alpha}$ radiation $(1486.6 \mathrm{eV})$. A spot size of $100 \mu \mathrm{m}$ was used in order to collect the photoelectron signal for both the high resolution (HR) and the survey spectra. Different pass energy values were exploited: $187.85 \mathrm{eV}$ for survey spectra and $23.5 \mathrm{eV}$ for HR peaks. All samples were analysed with a combined electron and argon ion gun neutralizer system, in order to reduce the charging effect during the measurements. The semi-quantitative atomic compositions and deconvolution procedures were obtained using Multipak 9.6 dedicated software. All core level peak energies were referenced to $\mathrm{C} 1 \mathrm{~s}$ peak at $284.5 \mathrm{eV}(\mathrm{C}-\mathrm{C} / \mathrm{C}-$ $\mathrm{H} \mathrm{sp}^{2}$ bonds) and the background contribution has been subtracted by means of a Shirley function. C1s components peak position, relative percentage (\%) and assignation to each chemical shift obtained from each deconvolution procedure have been studied [25].

\subsection{Field Emission Scanning Electron Microscopy (FESEM)}

Field Emission Scanning Electron Microscopy (FESEM) (Zeiss, Marlin) was performed to study the changes in structural morphology from cotton to carbon fibres. A conductive Cr coating $(5 \mathrm{~nm})$ was applied on the sample surface to avoid the charging effect and achieve the good resolution images. 


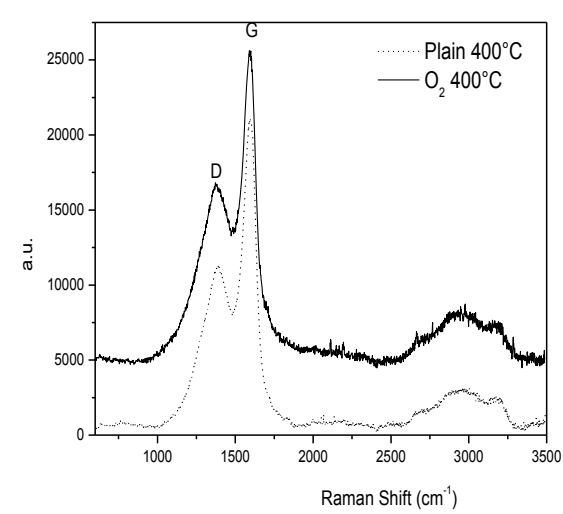

(a)

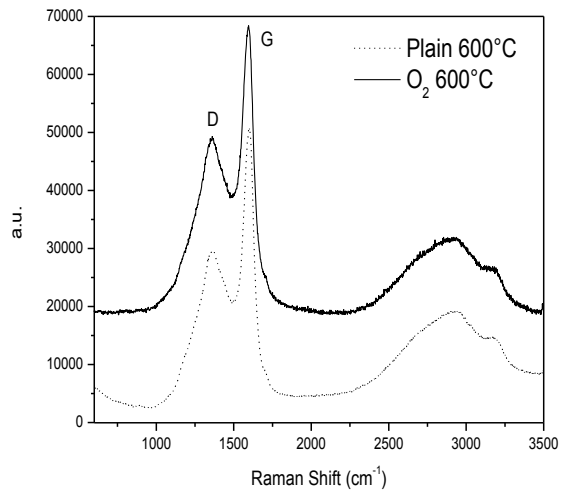

(b)

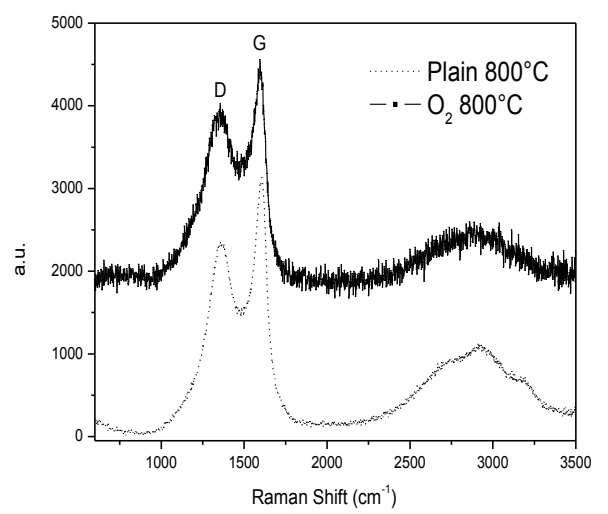

(c)

Fig. 5. Raman spectra of CFs and vacuum plasma treated CFs at (1) $400{ }^{\circ} \mathrm{C}$, (2) $600{ }^{\circ} \mathrm{C}$ and $(3) 800^{\circ} \mathrm{C}$.

\section{Results and discussion}

\subsection{Carbonisation of cotton fibres}

Carbonisation of cellulose refers to the conversion process from this depolymerised structure into graphite-like layers through re-polymerisation [22]. Figure 2 shows the carbonised residue obtained after pyrolysis of waste cotton fibres. Pyrolysis method allows converting cotton cellulose fibre to carbon fibres. After $400^{\circ} \mathrm{C}$, the weight loss is not significant. It indicates that almost the carbonisation process took place at $400^{\circ} \mathrm{C}$.

The carbonisation and graphitization of the fibres is a two-step process, i.e. low-temperature pyrolysis leads to carbonisation and high-temperature pyrolysis leads to graphitization [22]. This diversion of weight loss is representation of conversion for polymeric structure to carbonisation and initiation of graphitization. The final yield (wt.\%, Fig. 3) of carbonised fibres obtained after pyrolysis varies from $18.7( \pm 1.9) \mathrm{wt} . \%$ at $400^{\circ} \mathrm{C}, 16.5$ $( \pm 1.6)$ wt. $\%$ at $600{ }^{\circ} \mathrm{C}$ to $13.5( \pm 1.3)$ wt. $\%$ at $800^{\circ} \mathrm{C}$.

In pyrolysis, the schematic model depicted in Figure 2 interprets the deterioration steps of the cotton fibre layer. These changes are further studied in detail with FESEM. The cross section of the fibre is like bean-shaped [26]. Each cotton fibre is composed of concentric layers. The cuticle layer on the fibre itself is separable from the fibre and consists of wax and pectin materials. The primary wall of the fibre is composed of cellulosic crystalline fibrils [27-29]. The secondary wall of the fibre consists of closely packed parallel fibrils with cellulose within the fibre. The innermost part the lumen is composed of the remains of the cell contents [30].

\subsection{Thermo-gravimetric analysis (TGA)}

As a preliminary investigation, the TGA technique was applied to determine the threshold decomposition temperature as indicated by beginning weight loss and the temperature at the attainment of the limiting end point [31]. Initial weight loss (4wt.\%) in pyrolysis was observed between 25 and $150^{\circ} \mathrm{C}$ (Fig. 4). Dehydration and decomposition could be the first that takes place after one another. During this period, moisture leaves the cotton cellulose, and there is no adverse effect on the strength of the cellulose $[22,32,33]$. An initial mass change $(2 \mathrm{wt} . \%)$ in carbonisation process was observed before $100^{\circ} \mathrm{C}$. Dehydration of the cellulosic unit leads to the formation of the double-bonded intermediates [34]. The mass change in fibres starts by lowering the molecular weight [35] and may result in consequently low tensile strength [36]. For temperatures below $300{ }^{\circ} \mathrm{C}$, the decomposition proceeded very slowly with only $5 \mathrm{wt}$.\% losses. Above the limiting end, the rate of further weight loss of residual material increased considerably. This latter part of the reaction began at $300{ }^{\circ} \mathrm{C}$, which completed at $400^{\circ} \mathrm{C}$. Significant weight loss (73wt.\%) was observed before attainment of constant temperature. By Differential Thermogravimetric (DTG), the major weight loss was observed at $358^{\circ} \mathrm{C}$ followed by second minor weight loss of 6 wt. $\%$ at $410^{\circ} \mathrm{C}$. The basic microstructure of the carbon is formed between 300 and $450{ }^{\circ} \mathrm{C}$ [37]. Depolymerization to monosaccharide derivatives occurs during this stage of carbonisation. These intermediates form aromatic structures, releasing gases containing noncarbonated atoms $(\mathrm{O}, \mathrm{H})$ [38]. The carbonaceous residue is converted into a more ordered carbon structure through heat treatment between 450 and $800^{\circ} \mathrm{C} ; 6$ wt. \% losses were observed in this stage. Pyrolysis of cotton fibres up to $800^{\circ} \mathrm{C}$ causes the formation of semiordered carbonaceous structures (10 wt.\%). The representation of these changes in Figure 2 supports this phenomenon. The full mechanism of aromatization related to the graphitic products is still unknown, owing to the complex characterization of the cellulose decomposition and existence of many competing reactions during the different stages of carbonisation [39].

\subsection{Micro-Raman}

The Raman analysis (Fig. 5) was performed on carbon fibres prepared at three different temperatures (Fig. 5). The analysis shows three peaks. D-peak at $\sim 1350 \mathrm{~cm}^{-1}$ related to disordered $\mathrm{sp}^{3}$ carbon structure, G-peak at $\sim 1590 \mathrm{~cm}^{-1}$ related to $\mathrm{sp}^{2}$ graphitize structure and a wide peak between 2500 and $3200 \mathrm{~cm}^{-1}$ is related to second order combination band $[40,41]$ These peak positions are values 

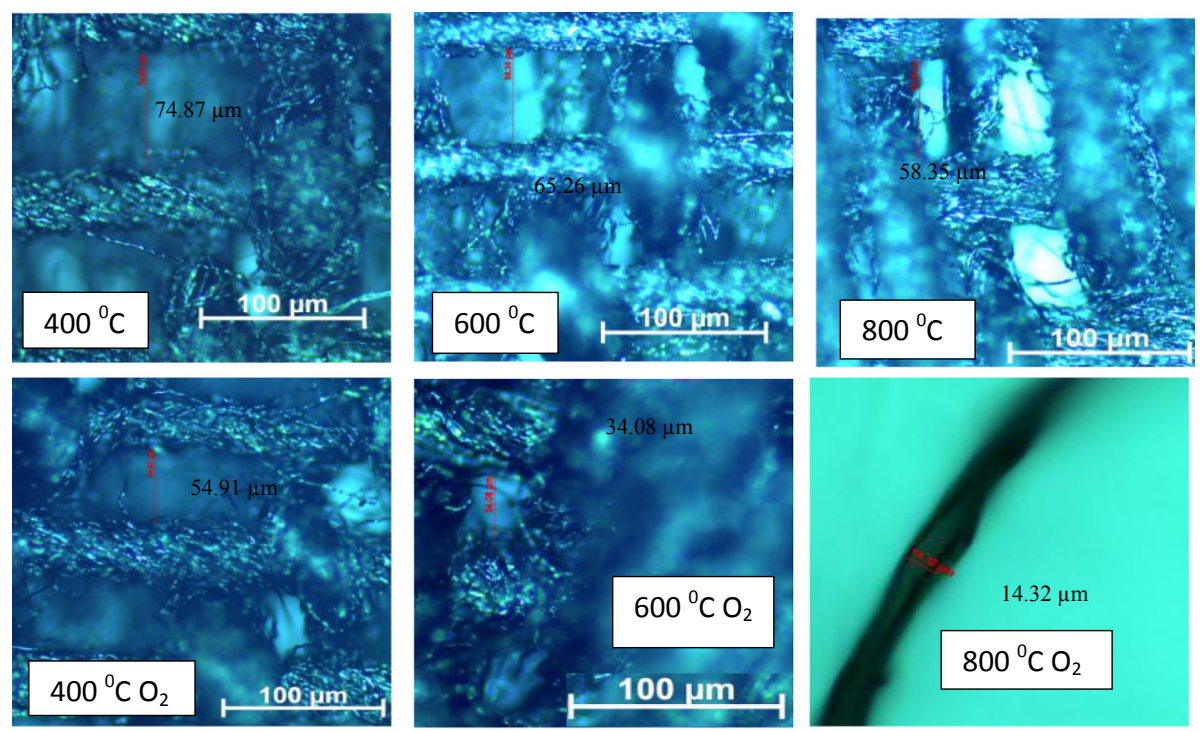

Fig. 6. CFs with depicted with a $\times 100$ lens with twisting of the single fibre depicted by a $\times 1000$ lens.

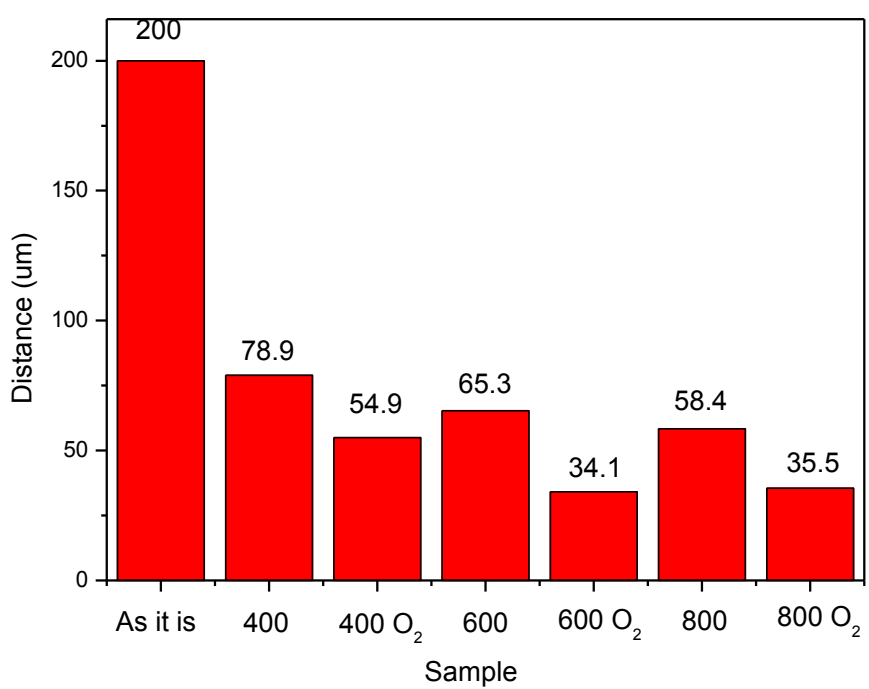

Fig. 7. Average distance between square ends of fibre weave using optical microscopy, for fibre shrinkage assessment (representative calculations as noted in Fig. 6).

for carbonised surface. No significant variation was observed in $\mathrm{sp}^{2}$ and $\mathrm{sp}^{3}$ peak positioning before and after plasma treatment. The reason might be due to negligible surface changes in the treatment or may be due to the partial crystal relaxation, as evidenced from the broadening of $\mathrm{D}$ and $\mathrm{G}$ bands.

Fibre shrinkage analysis was done by using Zeiss Optical Microscopy (Figs. 6-8). The distance between square ends of fibre weave is measured to study the shrinkage. Shrinkage in fibres is obvious with pyrolysis temperature (Fig. 7); plasma-treated CF shows further shrinkage. Fibre shrinkage in thermal treatment is attributed to loss of moisture and volatile compound, and transforming cellulosic chain into carbon chain is one of them. Figure 7 represents the schematic presentation of the shrinkage (shrinkage is also confirmed by TGA (Fig. 4) and FESEM analysis).

\subsection{Field Emission Scanning Electron Microscopy (FESEM)}

Field Emission Scanning Electron Microscopy (FESEM) was performed to visualize topographic details on the fibre surface. The structural analysis of cotton fibres, carbonised fibres, and plasma-treated carbon fibres was performed by FESEM (Tab. 2). As discussed earlier in Figure 2, cross section of the fibre was studied (Tab. 2, cross section column). This analysis confirms that the fibres are straight, twisted bean-like shape as shown in Figure 2. The diameter or cross sectional hyperbolic length of a cotton fibre is $\sim 12.0$ $( \pm 0.5) \mu \mathrm{m}$. The dimension changes with increase in pyrolysis temperature. It varies from $\sim 9.0( \pm 0.5) \mu \mathrm{m}$ at $400^{\circ} \mathrm{C}, \sim 7.0$ $( \pm 0.5) \mu \mathrm{m}$ at $600^{\circ} \mathrm{C}$ to $\sim 5.0( \pm 0.5) \mu \mathrm{m}$ at $800^{\circ} \mathrm{C}$. The results are in agreement with previous discussion of weight losses in different pyrolysis temperatures (Figs. 2 and 3) and TGA (Fig. 4). Carbon fibres pyrolysed at $800^{\circ} \mathrm{C}$ shows the fine hollow channels $\sim 2.5( \pm 0.1) \mu \mathrm{m}$. The external wall thickness is $\sim 1( \pm 0.05) \mu \mathrm{m}$. The hollow structure is absent in other fibres. Vacuum plasma-treated carbon fibres are not showing significant structural changes than that of carbon fibres without plasma treatment. It may be possible that the changes on carbon fibres surface are so insignificant that they cannot be identified by FESEM.

\subsection{X-ray Photoelectron Spectroscopy (XPS)}

Carbon fibre surface (with or without plasma treatment) analysis has been carried out by XPS to evaluate the changes in the chemical state. Survey spectra (Fig. 9, up row) of the untreated plasma samples show the presence of carbon and oxygen. The relative concentration of oxygen decreases by increasing the pyrolysis temperature: from 12.9 at. $\%$ for the carbon fibre pyrolysed at $400^{\circ} \mathrm{C}$ to 6.7 at. $\%$ for the carbon fibre pyrolysed at $800^{\circ} \mathrm{C}$. After the $\mathrm{O}_{2}$ plasma treatment (Fig. 10, down row), as expected, the amount of $\mathrm{O}$ increases, following the same behavior as mentioned before: from 40.8 at. $\%$ for the carbon fibre pyrolysed at $400{ }^{\circ} \mathrm{C}$ to 29.9 at. $\%$ for the carbon fibre pyrolysed at $800^{\circ} \mathrm{C}$. 
Table 2. FESEM of carbonised and plasma-treated CFs.

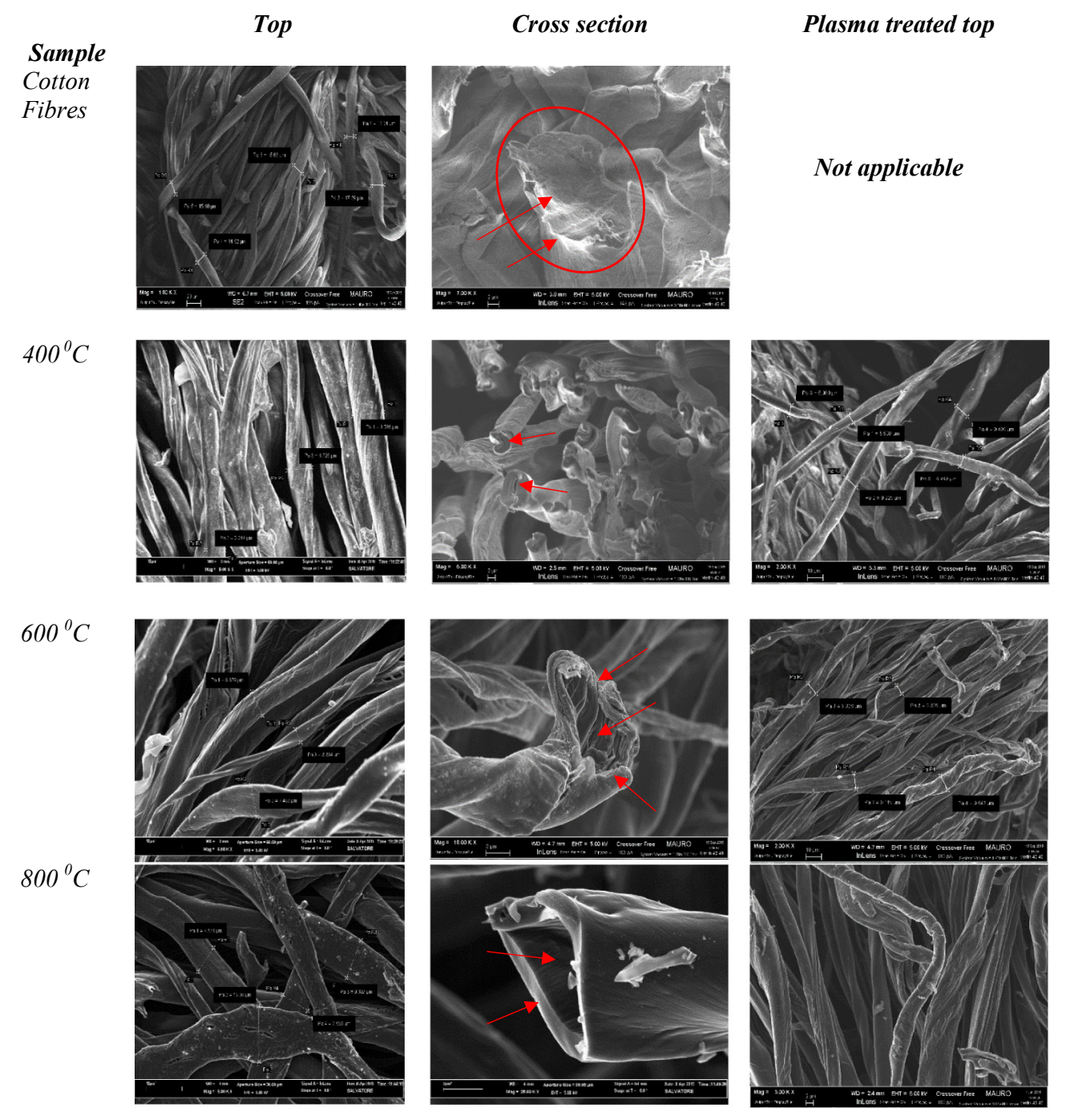

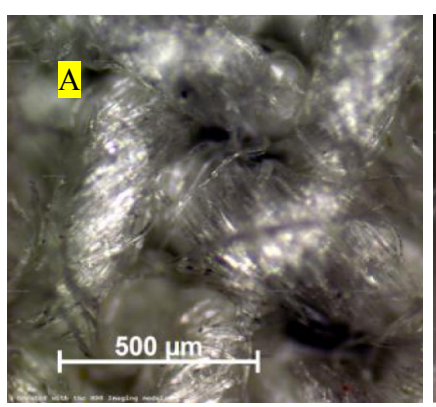

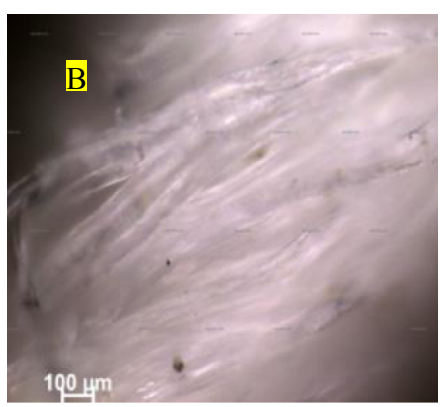

Fig. 8. Cotton fibres with (A) plain cellulose sample, depicted with $\mathrm{a} \times 100$ lens. $($ B) Plain cellulose sample, depicted with $\mathrm{a} \times 500$ lens.

HR spectra have been acquired to understand which kind of bonds are involved between carbon and oxygen (Fig. 10) and how they changes with respect to thermal and plasma treatments.

The data extracted by curve fitting for each sample are reported in Table 3. Each $\mathrm{C} 1$ s curve has been deconvoluted using five curves (Gaussian-Lorentzian sum function). The
$\mathrm{C}-(\mathrm{C} / \mathrm{H})$ component ( $\mathrm{sp}^{2}$ allotropic form $)$ at $284.5 \mathrm{eV}$ is the most abundant in all the samples and increases according to the increase in the thermal treatment temperature.

The second $(\mathrm{C}-\mathrm{O}-\mathrm{C} / \mathrm{H})$ component at $285.5-286.2 \mathrm{eV}$ decreases drastically with increasing temperature, while the third one $(\mathrm{C}=\mathrm{O})$ at $286.5-287.4 \mathrm{eV}$ remains almost constant in the two samples series (without and with plasma treatment respectively). The fourth $(\mathrm{C}-\mathrm{O}-\mathrm{C}=\mathrm{O})$ component at $288.0-288.7 \mathrm{eV}$ is almost constant in the untreated plasma samples, while it is scattered in the treated one. Then for the plasma-treated samples, there is a further component, which is not present for the untreated one, at $288.8-289.0 \mathrm{eV}$ due to $\mathrm{H}-\mathrm{O}-\mathrm{C}=\mathrm{O}$ bond, which does not present a peculiar trend in its abundance.

For the untreated samples instead there is another component, called $\pi-\pi *$ (HOMO-LUMO) transition (Fig. 11, upper row), that is a characteristic shake-up line (satellite peak located at $\sim 6 \mathrm{eV}$ from $\mathrm{sp}^{2}$ peak) for carbon in aromatic compounds (e.g. aromatic rings), coming from the ring excited by the exiting photoelectrons. This feature is the fingerprint of extended delocalized electrons in the material. It is present in graphitic material 
A

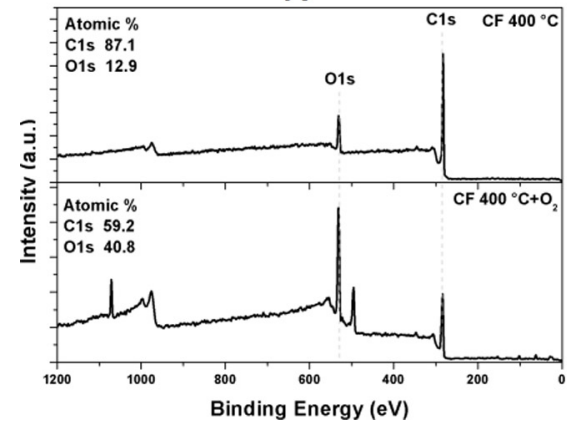

B

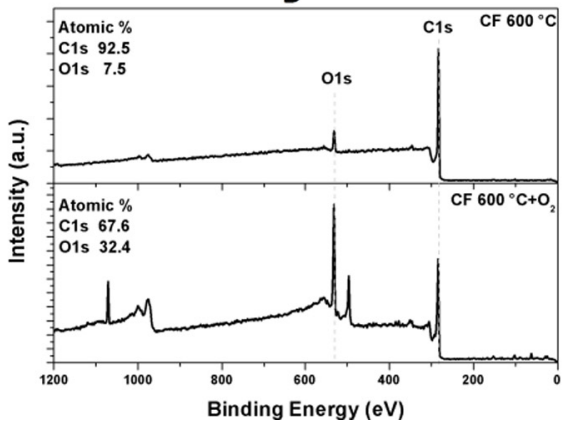

C

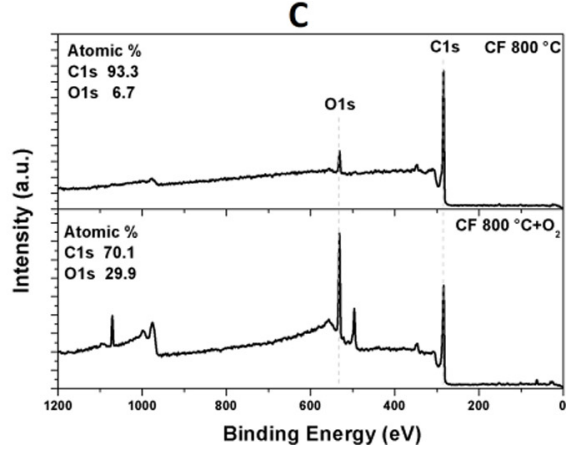

Fig. 9. XPS survey spectra for both the untreated (up) and plasma treated (down) samples: (A) $\mathrm{CF} 400^{\circ} \mathrm{C},(\mathrm{B}) \mathrm{CF} 600^{\circ} \mathrm{C}$ and $(\mathrm{C}) \mathrm{CF}$ $800^{\circ} \mathrm{C}$.

A

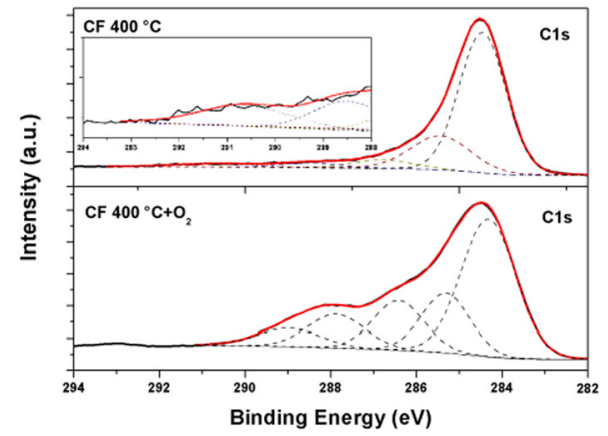

B

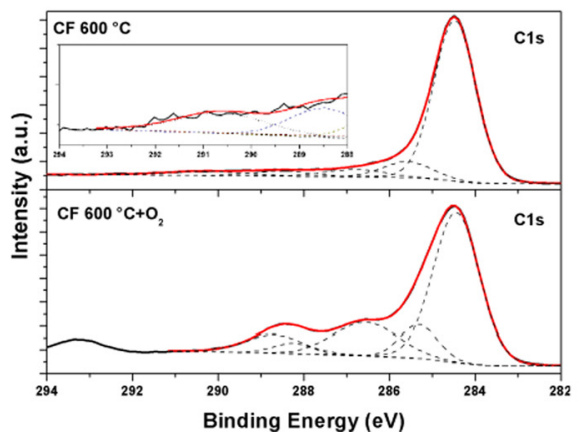

C

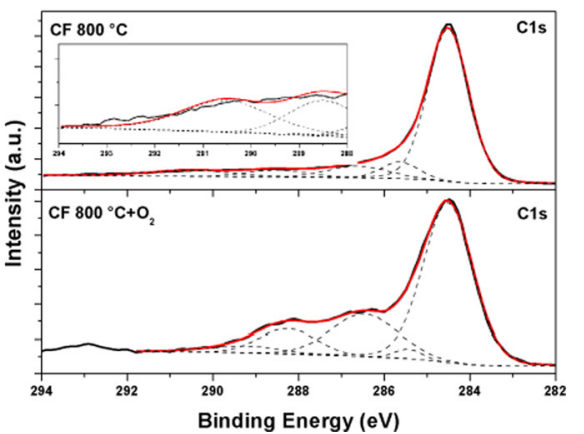

Fig. 10. XPS C1s HR spectra for both the untreated (up) and plasma treated (down) samples: (A) $\mathrm{CF} 400{ }^{\circ} \mathrm{C},(\mathrm{B}) \mathrm{CF} 600{ }^{\circ} \mathrm{C}$ and $(\mathrm{C})$ $\mathrm{CF} 800^{\circ} \mathrm{C}$.

HOPG (Highly Oriented Pyrolytic Graphite) [42] and CNT (Carbon Nano Tube) [43]. The $\pi-\pi *$ component increases by increasing the pyrolysis temperature, from $3.0 \%$ for the CF $400{ }^{\circ} \mathrm{C}, 4.6 \%$ for the $\mathrm{CF} 600^{\circ} \mathrm{C}$ to $6.6 \%$ for the $\mathrm{CF}$ $800^{\circ} \mathrm{C}$. For comparison, in the last row of Table 3, total percentage of $\mathrm{C}-\mathrm{O}$ bonds has been reported, confirming that the trend was already observed with the survey spectra.

\subsection{Surface wettability}

The surface wettability properties of the Carbon fibres were studied by using Glycerol (Fig. 11). Surface of all the pyrolysed carbon fibre shows the contact angle value above $100^{\circ}$, suggesting that the surfaces exhibit a hydrophobic nature $\left(\mathrm{CA}>90^{\circ}\right)[44]$ with low surface energy $[45,46]$. As many works have revealed, surface roughness plays an important role in determining the wetting behaviour of solid surfaces [47-49]. The hydrophobic surface is believed to be caused by the presence of synergistic binary geometric roughness at the micro/nanometer scale and the low surface energy functional groups, which reduce the surface energy. After modification of carbon fibre surface by oxygen in plasma treatment, contact angle of CF-400 and CF-800 reduced to $72\left( \pm 3.6^{\circ}\right)$ and $94.8\left( \pm 4.7^{\circ}\right)$, respectively. This indicates the surface modification with high-energy functional group, which increases the surface energy. Especially CF-400 changes from hydrophilic to hydrophobic. This behaviour better explained with XPS analysis (Tab. 3).
Looking at the analysis, it indicates that the functional group $(\mathrm{C}-\mathrm{O}-* \mathrm{C}=\mathrm{O})$ works as high-energy functional group. The functional group is more prominent values in 400 and $800^{\circ} \mathrm{C}$ treated carbon fibres. Carbon fibre treated at $600{ }^{\circ} \mathrm{C}$ has no evident surface modification with this group.

\subsection{Nanoindentation}

Samples treated in the same temperatures regardless of oxygen treatment, exhibit similar behaviour. Samples plain $600,600 \mathrm{O}_{2}$ and $800 \mathrm{O}_{2}$ presented repeatable results for a set of consecutive measurements, results that were also in correlation with the average gap dimensions measured by means of optical microscopy.

Resistance to applied load is a synergistic phenomenon of increasing stiffness and lubrication [50] (facilitation of fibres network movement under compression) due to pyrolysis process. In Figure 12, the maximum displacement of the carbon fibres at 400 is highest when compared to CF-600 and CF-800, for identical applied load. The CF600 has the least displacement (higher resistance to applied load). Enhancement of material strength after surface functionalization is evidenced for the case of CF-400 and no effect for CF800 and functionalized CF800. In CF-600, the strength (as means of resistance to applied load) of the CFs decreases after functionalization.

From 12, the different behaviour concerning elastoplasticity (as a means of energy revealing during experiment [51$53])$ is evident. There is no significant effect of $\mathrm{O}_{2}$ 
Table 3. XPS C1s components peak position and relative percentage (\%), for all the samples, obtained from each deconvolution procedure. Assignation to each chemical shift has been done according to [25].

\begin{tabular}{lcllllc}
\hline & \multicolumn{5}{c}{$\mathrm{C} 1 \mathrm{~s}$ components $(\%)$} \\
\cline { 2 - 7 } & $400{ }^{\circ} \mathrm{C}$ & $400{ }^{\circ} \mathrm{C}+\mathrm{O}_{2}$ & $600{ }^{\circ} \mathrm{C}$ & $600{ }^{\circ} \mathrm{C}+\mathrm{O}_{2}$ & $800{ }^{\circ} \mathrm{C}$ & $800{ }^{\circ} \mathrm{C}+\mathrm{O}_{2}$ \\
\hline $\mathrm{C}-(\mathrm{C} / \mathrm{H})(284.5 \mathrm{eV})$ & 66.6 & 46.8 & 77.0 & 58.3 & 72.7 & 61.8 \\
$\mathrm{C}-\mathrm{O}-(\mathrm{C} / \mathrm{H})(285.5-286.2 \mathrm{eV})$ & 21.7 & 18.0 & 9.6 & 10.5 & 7.4 & 2.0 \\
$\mathrm{C}=\mathrm{O}(286.5-287.4 \mathrm{eV})$ & 5.5 & 15.8 & 5.2 & 18.0 & 8.3 & 21.4 \\
$\mathrm{C}-\mathrm{O}-{ }^{\S} \mathrm{C}=\mathrm{O}(288.0-288.7 \mathrm{eV})$ & 3.2 & 12.0 & 3.6 & 3.5 & 5.0 & 10.8 \\
$\mathrm{H}-\mathrm{O}-{ }^{\S} \mathrm{C}=\mathrm{O}(288.8-289.0 \mathrm{eV})$ & - & 7.4 & - & 9.7 & - & 4.0 \\
$\pi-\pi *(>290 \mathrm{eV})$ & 3.0 & - & 4.6 & - & 6.6 & - \\
$\mathrm{C}-\mathrm{O}$ bonds $(\%)$ & 30.4 & 53.2 & 18.4 & 41.7 & 20.7 & 38.2 \\
\hline
\end{tabular}

$\S$ highlights the bond interested in the reported chemical shift, where more than one $\mathrm{C}$ and $\mathrm{O}$ bond is involved.

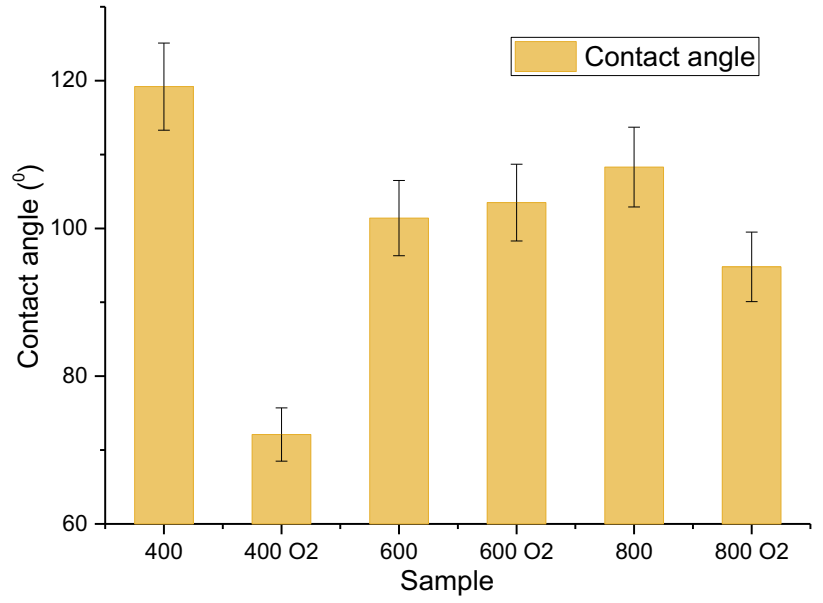

Fig. 11. Contact angle (glycerol) measurements on 400,600 and $800^{\circ} \mathrm{C} \mathrm{CFs}$ and plasma treated CFs.

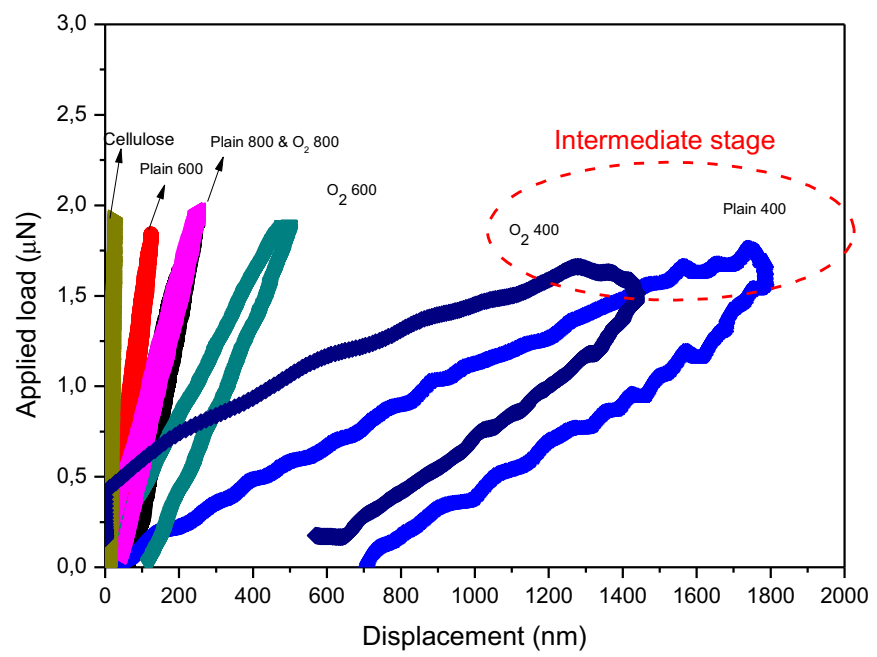

Fig. 12. Applied load versus displacement curves of cotton fibres, CFs and plasma-treated CFs by $\mathrm{O}_{2}$ (fabric form).
Table 4. Resistance to applied load for all samples.

\begin{tabular}{ll}
\hline & $\begin{array}{l}\text { Resistance to } \\
\text { applied load (GPa) }\end{array}$ \\
\hline Plain cellulose fabric & $6.4 \pm 0.3$ \\
Pyrolyzed $400^{\circ} \mathrm{C}$ & $5.4 \pm 0.2$ \\
Pyrolyzed $600^{\circ} \mathrm{C}$ & $5.8 \pm 0.3$ \\
Pyrolyzed $800^{\circ} \mathrm{C}$ & $5.6 \pm 0.2$ \\
\hline
\end{tabular}

functionalization at low temperature pyrolysis. Discrepancies are revealed only for the intermediate stage of $400^{\circ} \mathrm{C}$ pyrolysis, for both plain and functionalized fibres. Resistance to applied load for all samples is presented in Table 4. Plain cellulose fabric exhibits higher resistance to applied load (less displacement for identical load), while at $400^{\circ} \mathrm{C}$ pyrolysis, for both plain and functionalized fibres, the resistance decreases significantly; the predominant mechanism attributing to higher resistance to applied load at higher pyrolysis temperatures is the formation of a more ordered carbon structure through heat treatment between 450 and $800^{\circ} \mathrm{C}$, in line with the structural and thermal analysis above.

\section{Conclusions}

The CFs (14-17 wt.\%) conversion from waste cotton can be a good source for various applications. The surface and bulk property of $\mathrm{CF}$ change with pyrolysis temperature. One can choose the different carbon-containing CFs from waste Cotton with respect to application. XPS analysis confirms the surface modification by plasma treatment. Surface modification of CFs shows the change in surface and bulk properties. Bare CF showed larger contact angles than oxygen treated samples. It leads to the conclusion that oxygen treated samples are more effectively wetted by glycerol than plain ones. Resistance to applied load is a synergistic phenomenon of increasing stiffness and lubrication (facilitation of fibres network movement under compression) due to pyrolysis process. In our case, plain cellulose fabric exhibits higher resistance to applied load (less displacement for identical load), while at $400{ }^{\circ} \mathrm{C}$ 
pyrolysis, for both plain and functionalized fibres, the resistance decreases significantly; the predominant mechanism attributing to higher resistance to applied load at higher pyrolysis temperatures is the formation of a more ordered carbon structure through heat treatment.

This work has partially received funding from the European Union's Horizon 2020 research and innovation program MODCOMP under Grant Agreement No. 685844 and EU FP7 Project "Functionalized Innovative Carbon Fibres Developed from Novel Precursors with Cost Efficiency and Tailored Properties" (FIBRALSPEC) under Grant Agreement No. 604248. Authors would like also to acknowledge Dr. Salvatore Guastella and Mr. Mauro Raimondo for FESEM analysis.

\section{References}

1. G. Dorez et al., J. Anal. Appl. Pyrol. 107, 323 (2014)

2. M. John, S. Thomas, Carbohydr. Polym. 71, 343 (2008)

3. O. Faruk et al., Prog. Polym. Sci. 37, 1552 (2012)

4. M.J. John, R.D. Anandjiwala, Polym. Compos. 29, 187 (2008)

5. R. Kozłowski, M. Władyka-Przybylak, Polym. Adv. Technol. 19, 446 (2008)

6. D.N.S. Hon, Cellulose 1, 1 (1994)

7. Fibre Organon (Fiber Economics Bureau, Inc., Arlington, VA, 2004)

8. E.B. Cowling, in Advances in Chemistry, Series 95, edited by G.J. Hajny, E.T. Reese (ACS Publication, Washington, 1969)

9. A. Isci, G.N. Demirer, Renew. Energy 32, 750 (2007)

10. J.A.G. Varhegyi, M.J. Antal, E. Jakab, P. Szabo, Appl. Pyrol. 42, 73 (1997)

11. C. Charitidis et al., NanoWorld J. 1, 88 (2015)

12. H.O. Pierson, in Handbook of Carbon, Graphite, Diamonds and Fullerenes, edited by H.O. Pierson (Elsevier, New Jersey, 1994)

13. H. Honda, Carbon 26, 139 (1988)

14. E. Gkartzou, E.P. Koumoulos, C.A. Charitidis, Manuf. Rev. 4, 1 (2017)

15. S. Anagnou et al., Int. J. Struct. Integr. 7, 762 (2016)

16. M.I. Jahirul et al., Energies 5, 4952 (2012)

17. A. Demirbas, Fuel Process. Technol. 88, 591 (2007)

18. A.-F.A. Trompeta, E.P. Koumoulos, I.A. Kartsonakis, C.A. Charitidis, Manuf. Rev. 4, 7 (2017)

19. T.N. Muradov, N.Z. Veziroglu, Int. J. Hydrog. Energy 33, $6804(2008)$

20. M.J. Shenton, G.C. Stevens, J. Phys. D: Appl. Phys. 34, 2761 (2001)

21. R. Shishoo, in Plasma Technologies for Textiles, 1st edn., edited by R. Shishoo (Woodhead Publishing Series, Elsevier, Cambridge, 2007)
22. S.J. Park, in Carbon Fibers, edited by S.J. Park (Springer, New York, 2015)

23. M.S.A. Rahaman, A.F. Ismail, A. Mustafa, Polym. Degrad. Stab. 92, 1421 (2007)

24. E.P. Koumoulos, C.A. Charitidis, Appl. Surf. Sci. 396, 681 (2017)

25. D. Briggs, G. Beamson, Anal. Chem. 64, 1729 (1992)

26. P.J. Wakelyn, Cotton Fiber Chemistry and Technology (CRC Press, Boca Raton, 2006)

27. A.R. Bunsell, Handbook of Tensile Properties of Textile and Technical Fibres (Elsevier Science, Woodhead Publishing Series in Textiles, Cambridge, 2009)

28. M.J. Schick, Surface Characteristics of Fibers and Textiles (CRC Press, USA, 1977)

29. U.S.A.M.S.C. Division and U.S.B. of Agricultural Economics, The classification of cotton (U.S. Dept. of Agriculture, 1965)

30. J.W.S. Hearle, J. Polym. Sci. C: Polym. Symp. 20, 215 (2007)

31. P.K.C.C.M. Conrad, Text. Res. J. 36, 487 (1966)

32. C.H. Wu, C.-Y. Chang, J.-P. Lin, J. Chem. Technol. Biotechnol. 68, 65 (1997)

33. G. Várhegyi, M.J. Antal, E. Jakab, P. Szabó, J. Anal. Appl. Pyrol. 42, 73 (1997)

34. J. Scheirs, G. Camino, W. Tumiatti, Eur. Polym. J. 37, 933 (2001)

35. S.C. Naithani, N.R. Rao, Y.D. Singh, Physiol. Plant. 54, 225 (1982)

36. Y.L. Hsieh, X.-P. Hu, A. Wang, Text. Res. J. 70, 682 (2000)

37. R. Bacon, M.M. Tang, Carbon 2, 221 (1964)

38. J.A. Lie, M.-B. Hägg, J. Membr. Sci. 284, 79 (2006)

39. X. Huang, Materials 2, 2369 (2009)

40. A.C. Ferrari, J. Robertson, Phys. Rev. B. 61, 14095 (2000)

41. A.C. Ferrari, J. Robertson, Philos. Trans. A: Math. Phys. Eng. Sci. 3622477 (2004)

42. E.M. Baran Eren et al., J. Nanotechnol. 3, 852 (2012)

43. K.A. Wepasnick et al., Anal. Bioanal. Chem. 396, 1003 (2010)

44. W.K. Cho, S. Park, S. Jon, I.S. Choi, Nanotechnology 18, 395602 (2007)

45. L.Y. Meng, S.-J. Park, Macromol. Res. 19, 209 (2011)

46. J. Qu, L. He, Carbohydr. Polym. 98, 1056 (2013)

47. L.Y. Meng et al., Microporous Mesoporous Mater. 142, 26 (2011)

48. R. Blossey, Nat. Mater. 2, 301 (2003)

49. L.Y. Meng, S.J. Park, J. Colloid Interface Sci. 342, 559 (2010)

50. E.P. Koumoulos, P. Jagadale et al., Compos. B: Eng. 80, 27 (2015)

51. E.P. Koumoulos et al., Polym. Compos. 36, 1432 (2015)

52. E.P. Koumoulos, I.A. Kartsonakis, A. Bakolas, C.A. Charitidis, Manuf. Rev. 3, 20 (2016)

53. I.A. Kartsonakis, E.P. Koumoulos, C.A. Charitidis, Manuf. Rev. 4, 2 (2017)

Cite this article as: Pravin Jagdale, Elias P. Koumoulos, Irene Cannavaro, Aamer Khan, Micaela Castellino, Dimitrios A. Dragatogiannis, Alberto Tagliaferro, Costas A. Charitidis, Towards green carbon fibre manufacturing from waste cotton: a microstructural and physical property investigation, Manufacturing Rev. 4, 10 (2017) 